\title{
Europese regelgeving: meer dan de som der delen?*
}

\author{
Ellen Mastenbroek
}

\section{Achtergrond: de EU als een regulerende staat}

De EU is een regulatory state: een politiek systeem dat voornamelijk gebruikmaakt van regelgeving om beleidsdoelen te bereiken (Majone, 1994; Moran, 2002). Veel van deze regelgeving komt tot stand om functionele redenen: het oplossen van interdependente maatschappelijke problemen. Zo beoogt het Europese visserijbeleid de visstand in Europese wateren te beschermen en de richtlijn inzake luchtkwaliteit om onze volksgezondheid te verbeteren.

In weerwil van het beeld dat nationale politici en media regelmatig schetsen, komt deze Europese regelgeving niet als een 'Brusselse boodschap' uit de lucht vallen. Europese regelgeving komt tot stand met behulp van talloze Europese en nationale stakeholders, waaronder nationale overheden, parlementen, belangengroepen, bedrijven en burgers (Princen, 2014). Gezamenlijk opereren zij als radars in een succesvolle beleidsmachine: (Richardson, 2015, p. 27). Vrijwel alle beleidsvelden kennen tegenwoordig een Europese component (Bickerton, Hodson, \& Puetter, 2015, p. 703; Schmitter, 2005, p. 268), als zij al niet volledig zijn ge-europeaniseerd.

Tegelijkertijd storen veel burgers en politici zich aan de oprukkende macht van de EU. De periode van permissive consensus, stilzwijgende instemming met het Europese integratieproject, heeft plaatsgemaakt voor afnemende steun voor Europese integratie, gecombineerd met toenemende binnenlandse politisering (Hooghe \& Marks, 2009). De kritische houding ten aanzien van Europese integratie is enerzijds te herkennen als lage 'input-legitimiteit': negatieve percepties over het democratisch gehalte van de EU (Scharpf, 1999, p. 6). Een tweede kwetsbaar punt betreft de legitimiteit van de outputs van het Europese politieke systeem: de regelgeving (Scharpf, 1999, p. 6).

De gebrekkige Europese legitimiteit uit zich in voortdurend debat over de inhoud en gevolgen van Europese regelgeving. Sommigen vinden dat Europese regelgeving niet ver genoeg gaat om maatschappelijke problemen daadwerkelijk op te lossen - neem de kritiek op fijnstofnormen (bijvoorbeeld Köhler, 2015) en visquota's (bijvoorbeeld Monbiot, 2015). Anderen vinden juist dat Europese regelgeving te ver gaat; zij richten zich op de aanpassingskosten die nationale overheden, doelgroepen en politici moeten maken. Bijna de helft van de Neder-

* Prof. dr. E. Mastenbroek is professor of European Public Policy aan de Radboud Universiteit, Institute for Management Research. Deze tekst is een bewerking van haar oratie: Mastenbroek, E. (2017). Meer dan de som der delen? Beschouwingen over de implementatie en evaluatie van Europese regelgeving (inaugurele rede, 15 september 2017). Nijmegen: Radboud University. Geraadpleegd van http://hdl.handle.net/2066/174343. 
landse ambtenaren met Europese taken ervaart een spanningsveld tussen Europese regels en nationale politieke wensen (Mastenbroek, Dörrenbächer, Van den Berg, \& Princen, 2017, p. 37). Volgens Schmidt (2006, p. 5) zijn onze nationale democratieën verworden tot podia voor 'politics, without policy'.

\section{Het belang van EU-evaluatieonderzoek}

Kortom, Europese regelgeving is enerzijds gestoeld op de wens van bonte coalities van actoren om gezamenlijk maatschappelijke problemen op te lossen (Richardson, 2015, p. 11). Anderzijds leveren andere bonte coalities kritiek op diezelfde regelgeving. Vanuit dit oogpunt van 'regulatory contestation' is een belangrijke vraag of en hoe deze regelgeving eigenlijk in de praktijk werkt en de gewenste effecten sorteert. Evaluatieonderzoek behandelt dergelijke vragen.

Op basis van het democratiemodel van Easton (1965) kunnen evaluaties twee belangrijke functies vervullen. Ten eerste kunnen ze de kennisbasis leveren voor politieke verantwoording, ofwel 'feedback' naar de kiezer (Coglianese, 2012, p. 11; Vedung, 1997, pp. 102-108). Ten tweede kunnen evaluaties worden gebruikt om regelgeving te verbeteren (Fitzpatrick, 2012, p. 479; Vedung, 1997, p. 109). Deze functie is bij uitstek relevant voor de EU, aangezien het onmogelijk is om complexe maatschappelijke problemen in een club van 28 (straks 27?) lidstaten met een paar pennenstreken op te lossen (Schmitter, 2005, p. 259; Versluis, 2016). Europese integratie is dan ook een continu proces van stapsgewijze introductie en aanpassing van regelgeving. Door de werking en implementatie van interventies te onderzoeken kunnen evaluaties input leveren aan dit proces; de tweede feedbackloop.

Mijn onderzoeksagenda voor de komende jaren vormt een afgeleide van dit belang van degelijke evaluatie van Europese regelgeving. Deze agenda zal zijn beslag krijgen in twee onderzoekslijnen: onderzoek naar ex-post wetsevaluaties uitgevoerd door de Europese Commissie, en eigen evaluatieonderzoek naar de implementatie van Europese regelgeving.

\section{Onderzoek naar ex-post wetsevaluatie in de EU}

Mijn eerste onderzoekslijn betreft het kritisch bestuderen van ex-post evaluatie door de Europese Commissie, een vervolg van eerder onderzoek met onder anderen Stijn van Voorst (Mastenbroek, Van Voorst, \& Meuwese, 2016; Van Voorst \& Mastenbroek, 2017; Zwaan, Van Voorst, \& Mastenbroek, 2016). Zo wil ik vaststellen in hoeverre ex-post evaluatie meer is dan 'ritualistic evaluation' (Rossi, Lipsey, \& Freeman, 2004, p. 20), ingegeven door de wens de legitimiteit van de EU te verstevigen in plaats van serieuze analyses gericht op daadwerkelijk leren of het afleggen van verantwoording. Concreet voorzie ik twee thema's.

Een eerste thema is in hoeverre de gewenste leer- en verantwoordingsfuncties van evaluaties in de praktijk daadwerkelijk tot stand komen. Eerder onderzoek (Zwaan et al., 2016) liet zien dat het Europees Parlement Commissie-evaluaties nauwelijks gebruikt voor verantwoordingsdoeleinden. Dit lijkt te komen door 
wantrouwen: het Europees Parlement zet, net als andere ingewijden, vraagtekens bij de objectiviteit van studies uit de koker van de Europese Commissie (Poptcheva, 2013; Stern, 2009, p. 72). Deze observaties vragen om een systematische studie naar de percepties onder stakeholders over objectiviteit en kwaliteit van EU-wetsevaluaties en de gevolgen hiervan voor het gebruik van evaluaties.

Een tweede thema is een kritische beoordeling van uitgevoerde wetsevaluaties. Deze lijn vloeit voort uit mijn eerdere bespiegelingen over de aard van Europese besluitvorming. Door het pluriforme, consensusgerichte karakter van Europese besluitvorming is veel Europese regelgeving nogal diplomatiek van aard (Grønnegaard Christensen, 2010, p. 3). Dit maakt het mogelijk dat nationale of decentrale overheden de regels verschillend interpreteren en toepassen (Bondarouk \& Liefferink, 2017; Bondarouk, Liefferink, \& Mastenbroek, 2019; Dörrenbächer, 2017; Sampson Thierry, 2019; Thomann, 2015). In dergelijke situaties is top-down evaluatieonderzoek lastig, vooral als deze op positivistische leest gestoeld is. Als we niet weten wat de precieze doelen, maatregelen of interventielogica van wetgeving zijn, hoe kunnen we deze dan evalueren op werking, implementatie of effectiviteit? In zulke gevallen zou een evaluatie op zijn minst moeten expliciteren wat volgens de evaluatieonderzoekers de beleidstheorie is. Nog passender zou zijn als de evaluatie responsief van aard is: een effectiviteitsevaluatie zou dan een inventarisatie van de doeleinden, maatregelen en werkingsmechanismen zoals geïnterpreteerd door betrokken actoren omvatten (Kassim \& Le Galès, 2010, p. 8). Zo'n evaluatie zou zich volgens deze gedachtegang wellicht niet moeten richten op conformiteit van nationale maatregelen met de Europese regelgeving, zoals het leeuwendeel van de EU-wetsevaluaties doet (Mastenbroek et al., 2016, p. 1339; Van Voorst \& Mastenbroek, 2017, p. 644), maar op performance: de mate waarin zij actoren in staat stellen beleidsproblemen op te lossen (Barrett, 2004). Ik wil onderzoeken in hoeverre deze bottom-up evaluatie-aanpak wordt toegepast in de praktijk. Mijn inschatting is dat op dit vlak nog veel te winnen is, aangezien eerder onderzoek uitwees dat de rol van stakeholders in ex-post evaluaties zeer beperkt is (Mastenbroek et al., 2016, p. 1341) - een markante stijlbreuk met het verder zeer inclusieve Europese beleidsproces (Richardson, 2015, p. 11).

\section{Eigen evaluatieonderzoek}

Ik kom nu bij mijn tweede onderzoekslijn: het zelf verrichten van ex-post evaluatieonderzoek. Dat zal lastig blijken als het om de effectiviteit van Europese regelgeving gaat, gezien de benodigdheid van domeinspecifieke kennis. Zo vereist het biologische expertise om te achterhalen hoe Europese natuurregelgeving de stand van bedreigde diersoorten beïnvloedt. Mijn meerwaarde als bestuurskundige ligt op een ander vlak: evaluaties van implementatie binnen de lidstaten als belangrijke voorwaarde voor het realiseren van grensoverschrijdende doelen.

Het uitvoeren van dergelijke 'procesevaluaties' is geen overbodige luxe. Neem het recente dieselschandaal, dat liet zien dat nationale toezichthouders massaal hun ogen sloten voor systematische overtreding van Europese emissienormen door grote Europese autofabrikanten (Europees Parlement, 2017). Of neem de 
signalen over grootscheepse fraude met op Europees recht gebaseerde mestregelgeving ('Het mestcomplot', 2017). Diverse eerdere onderzoeken hebben laten zien dat nationale overheden bewuste strategieën hanteren om zich aan Europese verplichtingen te onttrekken (Mastenbroek, 2007; 2017; Sampson Thierry, 2019). Gezien deze problematiek wil ik onderzoek doen naar de effectiviteit van bestuurlijke interventies om nationale implementatie van Europese regels te bevorderen. Hierbij zal ik specifiek inzoomen op Europese overheidsnetwerken: netwerken van nationale overheidsorganisaties, gericht op het bevorderen van de nationale implementatie van Europese regelgeving. De gedachte is dat de nationale leden van dit soort netwerken van elkaar kunnen leren en door elkaar overtuigd of zelfs gedwongen zullen worden tot betere implementatie (Mastenbroek \& Sindbjerg Martinsen, 2018). Deze overheidsnetwerken, actief op vrijwel alle beleidsterreinen (Levi-Faur, 2011, pp. 818-822), symboliseren echter ook de paradox achter Europese integratie: nationale staten streven naar meer integratie, zonder al te veel zeggenschap kwijt te willen raken (Kelemen \& Tarrant, 2011). In de literatuur is dan ook een debat gaande over de effectiviteit van deze netwerken. Waar sommigen ze zien ze als veelbelovende governance tools (Hobolth \& Martinsen, 2013; Hofmann, 2008, p. 662; Maggetti \& Gilardi, 2014), stellen anderen dat deze netwerken een tandeloze tijger blijven (Kelemen \& Tarrant, 2011, p. 926).

Samen met Dorte Sindbjerg Martinsen zal ik de komende jaren onderzoeken ${ }^{1}$ hoe deze netwerken functioneren en of zij daadwerkelijk effect hebben op de nationale implementatie en handhaving van Europese regelgeving. Zo dragen we bij aan een antwoord op de vraag, in hoeverre Europese regelgeving meer is dan de som der delen.

\section{Literatuur}

Barrett, S.M. (2004). Implementation studies: time for a revival? Personal reflections on 20 years of implementation studies. Public Administration, 82(2), 249-262. doi: 10.1111/j.0033-3298.2004.00393.x

Berg, C. van den, Princen, S., \& Mastenbroek, E. (2016). Aan de knoppen maar uit de pas? Euroscepsis en euro-enthousiasme onder Nederlandse ambtenaren. Res Publica, 58(4), 397-422.

Bickerton, C.J., Hodson, D., \& Puetter, U. (2015). The new intergovernmentalism: European integration in the post-Maastricht era. Journal of Common Market Studies, 53(4), 703-722. doi:10.1111/jcms.12212

Blauberger, M., \& Rittberger, B. (2015). Conceptualizing and theorizing EU regulatory networks. Regulation \& Governance 9(4), 367-376. doi:10.1111/rego.12064

Bondarouk, E., Liefferink, D., \& Mastenbroek, E. (2019). Politics or management? Analysing differences in local implementation performance of the EU Ambient Air Quality directive. Journal of Public Policy. doi:10.1017/S0143814X19000035

Bondarouk, E., \& Liefferink, D. (2017). Diversity in sub-national EU implementation: The application of the EU Ambient Air Quality directive in 13 municipalities in the Netherlands. Journal of Environmental Policy \& Planning, 19(6), 733-753. doi: 10.1080/1523908X.2016.1267612 
Coglianese, C. (2012). Measuring regulatory performance: Evaluating the impact of regulation and regulatory policy (Expert Paper No. 1, August 2012). Paris: OECD.

Dörrenbächer, N. (2017). Europe at the frontline of migration law: Legal discretion, bureaucratic context and individual attitudes (doctoral dissertation). Nijmegen: Radboud University.

Easton, D. (1965). A systems analysis of political life. New York: John Wiley.

Europees Parlement. (2017). Verslag over het onderzoek naar emissiemetingen in de automobielsector (2016/2215(INI)). Brussel: Europees Parlement. Retrieved from http://www. europarl.europa.eu/sides/getDoc.do?pubRef=-//EP//TEXT+REPORT+A8-2017 $-0049+0+\mathrm{DOC}+\mathrm{XML}+\mathrm{V0} / / \mathrm{NL} \#$ title8

Fitzpatrick, T. (2012). Evaluating legislation: An alternative approach for evaluating EU internal market and services law. Evaluation, 18(4), 477-499. doi: $10.1177 / 1356389012460439$

Grønnegaard Christensen, J. (2010). EU legislation and national regulation: Uncertain steps towards a European public policy. Public Administration, 88, 3-17. doi:10.1111/j. 1467-9299.2010.01813.x

Haas, E.B. (1958). The uniting of Europe: Political, social and economic forces 1950-1957. London: Stevens \& Sons.

Het mestcomplot. (2017, 11 november). NRC Handelsblad. Retrieved from https://www. nrc.nl/nieuws/2017/11/10/het-mestcomplot-a1580703

Hobolth, M., \& Martinsen, D.S. (2013). Transgovernmental networks in the European Union: Improving compliance effectively? Journal of European Public Policy, 20(10), 1406-1424. doi:10.1080/13501763.2013.800791

Hofmann, H.C.H. (2008). Mapping the European administrative space. West European Politics, 31(4), 662-676. doi:10.1080/01402380801905918

Hooghe, L., \& Marks, G. (2009). A postfunctionalist theory of European integration: From permissive consensus to constraining dissensus. British Journal of Political Science, 39(1), 1-23. doi:10.1017/S0007123408000409

Kassim, H., \& Le Galès, P. (2010). Exploring governance in a multi-level polity: A policy instruments approach. West European Politics, 33(1), 1-21. doi: $10.1080 / 01402380903354031$

Kelemen, R.D., \& Tarrant, A.D. (2011). The political foundations of the Eurocracy. West European Politics, 34(5), 922-947. doi:10.1080/01402382.2011.591076

Köhler, W. (2015, 12 maart). Nederlanders sterven eerder door stikstof. NRC Handelsblad. Verkregen van https://www.nrc.nl/nieuws/2015/03/12/nederlanders-sterven-eerderdoor-stikstof-1477518-a683795

Levi-Faur, D. (2011). Regulatory networks and regulatory agencification: Towards a single European regulatory space. Journal of European Public Policy, 18(6), 810-829. doi: 10.1080/13501763.2011.593309

Maggetti, M., \& Gilardi, F. (2014). Network governance and the domestic adoption of soft rules. Journal of European Public Policy, 21(09), 1293-1310. doi: 10.1080/13501763.2014.923018

Majone, G. (1994). The rise of the regulatory state in Europe. West European Politics, 17(3), 77-101. doi:10.1080/01402389408425031

Mastenbroek, E. (2007). The politics of compliance: Explaining the transposition of EC directives in the Netherlands. Leiden: Leiden University. Retrieved from https://openaccess. leidenuniv.nl/handle/1887/11861

Mastenbroek, E. (2017). Guardians of EU law? Analysing roles and behaviour of Dutch legislative drafters involved in EU compliance. Journal of European Public Policy, 24(9), 1289-1307. doi:10.1080/13501763.2017.1314537 
Mastenbroek, E., \& Sindbjerg Martinsen, D. (2018). Filling the gap in the European administrative space: The role of administrative networks in EU implementation and enforcement. Journal of European Public Policy, 25(3), 422-435. doi: 10.1080/13501763.2017.1298147

Mastenbroek, E., Dörrenbächer, N., Berg, C. van den, \& Princen, S. (2017). Guardians of EU law? Analyzing the propensity of Dutch civil servants to comply with EU law. Policy implementation reloaded conference, University of Münster, 6-7 July 2017. Retrieved from http://www.ru.nl/personen/mastenbroek-e/

Mastenbroek, E., Voorst, S. van, \& Meuwese, A.C.M. (2016). Closing the regulatory cycle? A meta evaluation of ex-post legislative evaluations by the European Commission. Journal of European Public Policy, 23(9), 1329-1348. doi: 10.1080/13501763.2015.1076874

Monbiot, G. (2015, July 10). Why the EU's increasing failure to protect nature means I may vote no. The Guardian. Retrieved from https://www.theguardian.com/ environment/2015/jul/10/why-eus-increasing-failure-protect-nature-means-i-mayvote-no-referendum

Moran, M. (2002). Understanding the regulatory state. British Journal of Political Science, 32, 391-413. doi:10.1017/S0007123402000169

Poptcheva, E.M. (2013). Policy and legislative evaluation in the EU (Library Briefing). Brussels: European Parliament.

Princen, S.B. (2014). 'Het moet van Brussel': De verhouding tussen EU en lidstaten tussen retoriek en werkelijkheid (inaugurele rede, 3 oktober 2014). Utrecht: Universiteit Utrecht.

Richardson, J. (2015). The EU as a policy-making state: A policy system like any other? In J. Richardson \& S. Mazey (Eds.), European Union: Power and policy-making (4th edition, pp. 3-31). London: Routledge.

Rossi, P.H., Lipsey, M.W., \& Freeman, H.E. (2004). Evaluation: A systematic approach . Thousand Oaks/London/New Delhi: Sage.

Sampson Thierry, J. (2019). Regaining control: Welfare state strategies against unwanted EU law (doctoral dissertation, University of Copenhagen, Department of Political Science). Retrieved from https://www.academicbooks.dk/en/content/regainingcontrol-1

Scharpf, F.W. (1999). Governing in Europe: Effective and democratic? Oxford: Oxford University Press.

Schmidt, V. (2006). Democracy in Europe: The EU and national politics. Oxford: Oxford University Press.

Schmitter, P.C. (2005). Ernst B. Haas and the legacy of neofunctionalism. Journal of European Public Policy, 12(2), 255-272. doi:10.1080/13501760500043951

Stern, E. (2009). Evaluation policy in the European Union and its institutions. In W.M.K. Trochim, M.M. Mark \& L.J. Cooksy (Eds.), Evaluation policy and evaluation practice: New directions for evaluation (pp. 67-85). San Francisco, CA: Jossey-Bass.

Swanborn, P.G. (2007). Evalueren: Het ontwerpen, begeleiden en evalueren van interventies: een methodische basis voor evaluatie-onderzoek (2e druk). Amsterdam: Boom Onderwijs.

Thomann, E. (2015). Customizing Europe: Transposition as bottom-up implementation. Journal of European Public Policy, 22(10), 1368-1387. doi: 10.1080/13501763.2015.1008554

Vedung, E. (1997). Public policy and program evaluation. New Brunswick: Transaction Publishers.

Versluis, E. (2016). The European regulatory state at risk? The EU as a regulator of complex policy problems (inaugurele rede). Maastricht: Maastricht University. doi:10.13140/ RG.2.1.1132.8408 
Voorst, S. van, \& Mastenbroek, E. (2017). Enforcement tool or strategic instrument? The initiation of ex-post legislative evaluations by the European Commission. European Union Politics, 18(4), 640-657. doi:10.1177/1465116517725901

Zwaan, P., Voorst, S. van, \& Mastenbroek, E. (2016). Ex-post regulatory evaluation in the European Union: Questioning the use of evaluations as instruments for accountability. International Review of Administrative Sciences, 82(4), 674-693. doi: 10.1177/0020852315598389 